\title{
Comparison of Multilayer Perceptron and Radial Basis Function Neural Networks in Predicting the Success of New Product Development
}

\author{
Golamreza Soltani Fesghandis \\ Department of Management \\ Ferdowsi University of \\ Mashhad \\ Mashhad, Iran \\ rsoltani359@gmail.com
}

\author{
Alireza Pooya \\ Department of Management \\ Ferdowsi University of \\ Mashhad \\ Mashhad, Iran \\ alirezapooya@um.ac.ir
}

\author{
Mostafa Kazemi \\ Department of Management \\ Ferdowsi University of \\ Mashhad \\ Mashhad, Iran \\ kazemi@um.ac.ir
}

\author{
Zahra Naji Azimi \\ Department of Management \\ Ferdowsi University of \\ Mashhad \\ Mashhad, Iran \\ znajiazimi@um.ac.ir
}

\begin{abstract}
Given that the new product failure in practice entails huge costs for organizations, the need for competitive planning has led organizations to apply appropriate approaches; one of these approaches is to predict new product success before market entry. Accordingly, this study predicts NPD success by comparing two techniques, the Multilayer Perceptron (MLP) and the Radial Basis Function (RBF) in the clothing industry of Tabriz. In order to collect data, a questionnaire with good validity and reliability was distributed among the population. MLP and RBF were used to analyze data. Based on MSE, RMSE and R2, data analysis showed that MLP had lower error than RBF in predicting NPD success.
\end{abstract}

Keywords-new product development; success prediction; artificial neural network.

\section{INTRODUCTION}

Rapid technological changes, intense competition, dynamic customer needs and low demand of outdated products available have led to shorter product life cycle [1]. Ability of New Product Development (NPD) is very important to succeed in the current turbulent environment [2]. Contemporary management literature often stresses the need for innovation and NPD to compete in changing markets [3]. Among a variety of product development processes, NPD has its own complexities, including lack of knowledge of developers and product designers, which necessarily increases only during development time [4]. NPD is an opaque and complex process which involves almost all departments of an enterprise such as marketing, design and engineering, manufacturing and so on. When it comes to new product, a wide range of concepts, from a simple consumable product to a new very complex military system, comes to mind. There are as many NPD models as the number of people who have addressed this field of research [5]. NPD processes are the most challenging activities of an organization due to unforeseen or unknown obstacles in terms of technology and business risks. Most of these are because of the fact that knowledge of organizations always evolves during NPD projects and there is no deep understanding of what will happen in the future. Therefore, planning for this process is inherently dynamic and needs to adapt to changes in product knowledge as well as other changes [6, 7]. Despite many complexities developers and designers of new products face, unfortunately there are not enough tools for decision support in implementing NPD processes. In [8], the authors noted this in a review of more than 30 studies published; therefore, proper tools need to be developed to predict NPD success, as the prediction of NPD success is very important for industry leaders and organizations due to the high failure rate of NPD that reflects the complexity of NPD processes. For system identification and modeling of complex processes, scientists have been always concerned with input and output data. Soft computing techniques are used for modeling in these processes. Neural networks are well known components of soft computing techniques that are highly capable of control and identification of nonlinear complex systems. Several studies done in various fields using these techniques reflect the fact that they are both simple and highly capable [1,9-12]. With respect to simplicity and high capability of these techniques as well as absence of similar models in study and prediction of NPD success, predictive modeling of NPD success using artificial neural network and adoption of the best prediction technique will result in development of a practical model in this area.

\section{A. Effective Factors on NPD Success}

New products provide new ways and new opportunities for organizations to make a profit and hope to survive; however, important risks associated with NPD projects should not be neglected. Empirical studies show high failure rates for new products in consumer markets [13]. Nevertheless, expression of successes and victories is not only sweet but also provides credit for successful organizations. Obviously, successful managers are willing to discuss these factors as much as their strategic interests are not endangered and other managers tend to gain experience of successful organizations [14]. Lester [13] presents sixteen factors effective on NPD success, which can help managers to flee usual traps in NPD process and succeed in development of new products. In [14], the authors noted top management support for innovation, long-term strategy with an 
innovative focus, long-term commitment to larger projects, flexibility and responsiveness to change, risk taking by top management and support of an entrepreneurial culture as effective factors on NPD. Ten effective factors on NPD were presented in [15] and 11 in [16]. In [17], authors classified the success factors of a NPD project into four main categories and five sub-categories; they believed that main factors for success of a new product included a high quality NPD process, a welldefined (certain) strategy for business, adequate resources, human resources and money spent on research and development for NPD.

\section{B. Artificial Neural Network}

Artificial neural networks (ANNs) are mathematical models that are able to extract patterns in the observed data without the need for assumptions about the relationships between the various variables [18]. ANNs tend to present a mapping between the input space (input layer) and the optimal space (output layer) by understanding inherent relationships between data. Hidden layer(s) processes information received from input layer and delivers it to output layer. Each network is trained by receiving examples. Training is a process which leads to learning. Network learning occurs when communication weights between layers change, so that difference between predicted and calculated values is acceptable. Learning process occurs when these conditions are met. These weights express memory and knowledge of the network. A trained ANN can be used to predict outcomes proportional to a new set of data [19]. Based on ANN structure, its major features include fast processing, ability to learn the pattern by pattern will, ability to extend knowledge after learning, flexibility against unwanted errors and lack of significant disruption if a problem occurs in a part of connections due to weight distribution [20]. There are several types of ANNs; this study used Multilayer Perceptron (MLP) and radial basis function (RBF).

\section{Multilayer Perceptron (MLP)}

An MLP (Multilayer Perceptron) is formed of neurons grouped in an input layer, several hidden layers and an output layer. A neuron is connected from a layer to all neurons in the next layer; however, there is no connection between neurons in one layer. An ANN can have a number of hidden layers; theoretical research undertaken in this field showed that any complex and non-linear function could be approximated by a hidden layer for these models [21, 22]. Therefore, this study used a MLP with one hidden layer.

\section{Radial Basis Function (RBF)}

RBF networks need a large number of neurons for training. These networks best perform with a high number of training vectors. Unlike other networks, the entire input space of RBF is not responded similarly. Here, input space center is first calculated; then, inputs which are close enough to this center are responded. As a result, these networks respond to inputs locally. RBF has two layers; the first layer is radial basis and the output layer is linear. Training process is done by competitive learning or clustering. Network parameters include spread number and goal number. Network performance can be improved by changing these parameters. By applying inputs to the network, the distance between input vectors and weight vectors is calculated and vector product is obtained by multiplying the calculated values by bias values. Then, these values generate as many neurons as inputs by corresponding functions; finally, output values are obtained by output layer [23].

\section{METHODS AND MATERIALS}

This is an applied extensive research. Data was collected by using two questionnaires from 185 clothing manufacturers. The first questionnaire, based on [14], assessed effective factors on NPD success. The second questionnaire evaluated NPD success using the variables described in [24]. Input variables included effective factors on NPD success; output was NPD success. In order to evaluate potential ambiguities of questionnaires, four questionnaires were filled face to face with participation of researchers and some questions were modified. Finally, the questionnaires were given to university professors in order to obtain feedback on modifications, through which validity of the questionnaires was confirmed. Cronbach's alpha coefficient was used to determine reliability of the questionnaires. This test was performed on the original sample by separating constructs (Table I). The results indicate good reliability of the questionnaires.

TABLE I. CRONBACH'S ALPHA COEFFICIENT

\begin{tabular}{|c|c|}
\hline Questionnaire & Cronbach's alpha \\
\hline Effective factors on NPD success & 0.856 \\
\hline NPD success & 0.792 \\
\hline
\end{tabular}

MLP and RBF were used to analyze data. In order to compare performance of each ANN, $\mathrm{R}^{2}$, MSE and RMSE were calculated as follows.

$$
\begin{gathered}
\mathrm{R}^{2}=1-\frac{\sum_{k=1}^{n}\left(u_{a, k}-u_{p, k}\right)^{2}}{\sum_{k=1}^{n}\left(u_{a, k}\right)^{2}} \\
\mathrm{MSE}=\frac{\sum_{k=1}^{n}\left(u_{a, k}-u_{p, k}\right)^{2}}{n} \\
\mathrm{RMSE}=\sqrt{\frac{\sum_{k=1}^{n}\left(u_{a, k}-u_{p, k}\right)^{2}}{n}}
\end{gathered}
$$

where, $u_{p, k}$ represents the predicted value by each model, represents actual data and represents the number of observations.

\section{RESULTS}

\section{A. Prediction of NPD Success Using MLP}

Considering six input variables (top management support for innovation, long-term strategy with innovative focus, longterm commitment to larger projects, flexibility and responsiveness to change, risk taking by top management, and support of an entrepreneurial culture) and an output variable as success of new product performance, ANN structure was implemented with six input variables, a hidden layer and an 
output variable in MATLAB software (Figure 1). To evaluate the performance of the MLP, the number of neurons increased in hidden layer by trial and error. The best performance of MLP based on MSE, RMSE and $\mathrm{R}^{2}$ is shown in Table II. A comparison of each MLP based on above indexes shows that increase of neurons to eight in the hidden layer reduced error and increased $\mathrm{R}^{2}$. Then, network error increased and $\mathrm{R}^{2}$ was reduced. Therefore, the best MLP to predict NPD success was the network with eight neurons in the hidden layer. The results are shown in Figures 2 and 3.

\section{B. Prediction of NPD Success Using RBF}

Given that maximum number of neurons was equal to the number of samples, RBF was designed and trained with six primary neurons. Increase in the number of neurons reduced error and increased $\mathrm{R}^{2}$. Table III shows the results for RBF with different number of neurons.

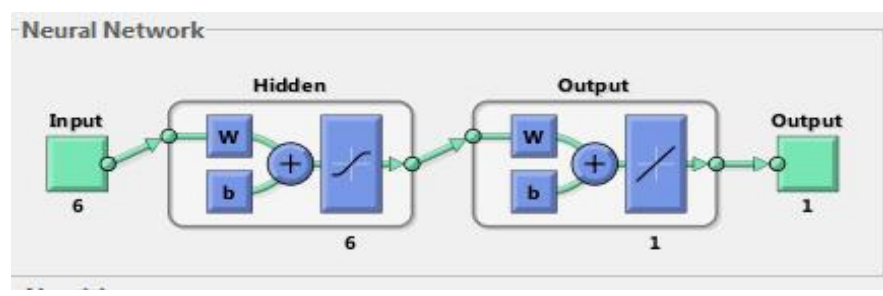

Fig. 1. ANN structure to predict NPD success

TABLE II. MLP PERFORMANCE WITH DIFFERENT NUMBER OF NEUTRONS IN THE HIDDEN LAYER

\begin{tabular}{|c|c|c|c|c|}
\hline Number of neurons & Type of data & $R^{2}$ & $R M S E$ & $M S E$ \\
\hline \multirow{2}{*}{6} & Training & 0.55083 & 0.58331 & 0.34025 \\
\cline { 2 - 5 } & Test & 0.24033 & 0.76516 & 0.58547 \\
\hline \multirow{2}{*}{7} & Training & 0.47138 & 0.58657 & 0.34441 \\
\cline { 2 - 5 } & Test & 0.43308 & 0.80611 & 0.64981 \\
\hline \multirow{2}{*}{8} & Training & 0.68277 & 0.47439 & 0.22505 \\
\cline { 2 - 5 } & Test & 0.49852 & 0.72450 & 0.52490 \\
\hline \multirow{2}{*}{9} & Training & 0.57937 & 0.54498 & 0.29701 \\
\cline { 2 - 5 } & Test & 0.38444 & 0.73256 & 0.53664 \\
\hline \multirow{2}{*}{10} & Training & 0.58866 & 0.53615 & 0.28746 \\
\cline { 2 - 5 } & Test & 0.41011 & 0.81013 & 0.65632 \\
\hline \multirow{2}{*}{20} & Training & 0.59666 & 0.59441 & 0.35332 \\
\cline { 2 - 5 } & Test & 0.152116 & 0.83396 & 0.69548 \\
\hline \multirow{2}{*}{50} & Training & 0.51264 & 0.87912 & 0.77285 \\
\cline { 2 - 5 } & Test & 0.00299 & 1.3843 & 1.9163 \\
\hline
\end{tabular}
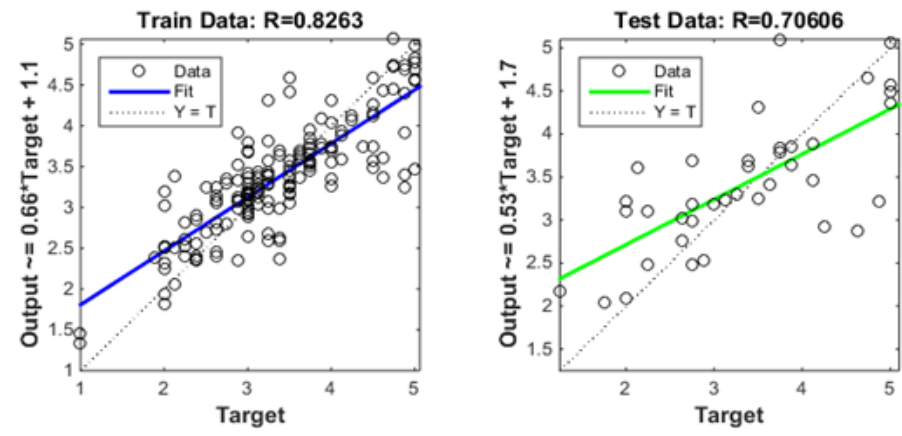

Fig. 2. The calculated correlation between actual data and output data for the neural network with eight neurons

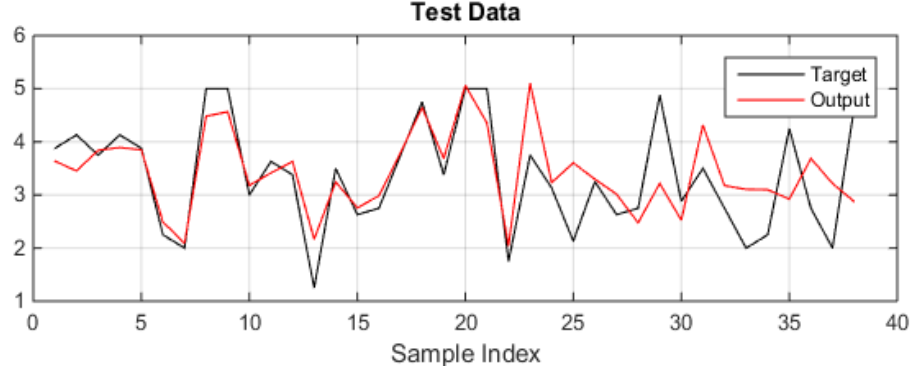

MSE $=0.5249$, RMSE $=0.7245$

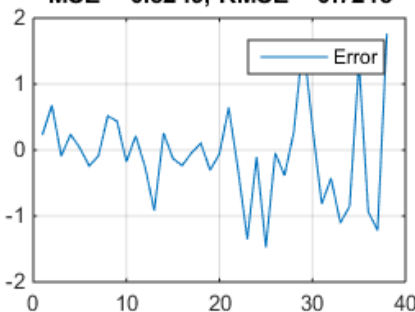

Error Mean $=-0.073726$, Error St.D. $=0.73041$

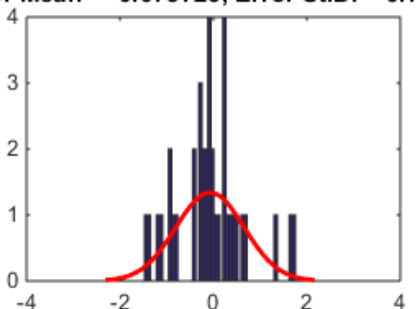

Fig. 3. Results for MLP training data with eight neurons

TABLE III. RBF PERFORMANCE WITH DIFFERENT NUMBER OF NEUTRONS

\begin{tabular}{|c|c|c|c|c|}
\hline Number of neurons & Type of data & $R^{2}$ & $R M S E$ & $M S E$ \\
\hline \multirow{2}{*}{6} & Training & 0.10284 & 0.79981 & 0.63969 \\
\cline { 2 - 5 } & Test & 0.07782 & 0.84492 & 0.71388 \\
\hline \multirow{2}{*}{7} & Training & 0.12214 & 0.79226 & 0.62767 \\
\cline { 2 - 5 } & Test & 0.00088 & 0.83857 & 0.70320 \\
\hline \multirow{2}{*}{8} & Training & 0.14074 & 0.78883 & 0.62225 \\
\cline { 2 - 5 } & Test & .06088 & 0.80154 & 0.64247 \\
\hline \multirow{2}{*}{9} & Training & 0.15898 & 0.77519 & 0.60092 \\
\cline { 2 - 5 } & Test & 0.11976 & 0.84427 & 0.71278 \\
\hline \multirow{2}{*}{10} & Training & 0.17248 & 0.76483 & 0.58497 \\
\cline { 2 - 5 } & Test & 0.15954 & 0.86481 & 0.74790 \\
\hline \multirow{2}{*}{20} & Training & 0.34640 & 0.48824 & 0.34727 \\
\cline { 2 - 5 } & Test & 0.12060 & 0.88313 & 0.77993 \\
\hline \multirow{2}{*}{50} & Training & 0.60516 & 0.53735 & 0.28864 \\
\cline { 2 - 5 } & Test & 0.09820 & 0.94692 & 0.89667 \\
\hline \multirow{2}{*}{100} & Training & 0.80718 & 0.37397 & 0.13986 \\
\cline { 2 - 5 } & Test & 0.10586 & 1.0848 & 1.1768 \\
\hline \multirow{2}{*}{225} & Training & 1 & 0.00000 & 0.00000 \\
\cline { 2 - 5 } & Test & 0.67179 & 0.43164 & 0.18631 \\
\hline
\end{tabular}

As shown in Table III, an increase in the number of neurons reduced MSE and RMSE and increased $\mathrm{R}^{2}$. According to the results, best network performance occurred in 225 neurons and the training error was zero. In other words, RBF with 225 neurons presented output data proportional to actual data $\left(\mathrm{R}^{2}=1\right)$ and a full training took place as shown in Figures 4 and 5. In order to choose the best ANN, the best network in terms of MSE, RMSE and $\mathrm{R}^{2}$ was selected and the results were compared. The results of comparison are shown in Table IV. Table 4 shows that the best method to predict NPD success is RBF.

\section{CONCLUSION}

Due to the high failure rate of new products and the need for a technique to predict New Product Development (NPD) success before spending high cost and wasting corporate resources, this study presented a model to predict NPD success 
using Artificial Neural Networks. The networks were designed and implemented based on the Multilayer Perceptron and the Radial Basis Function architecture. The comparison of two models showed that the Radial Basis Function network provides a better prediction with lower error. Therefore, corporate executives, particularly cloth manufacturers, are recommended to predict new products' success beforehand.
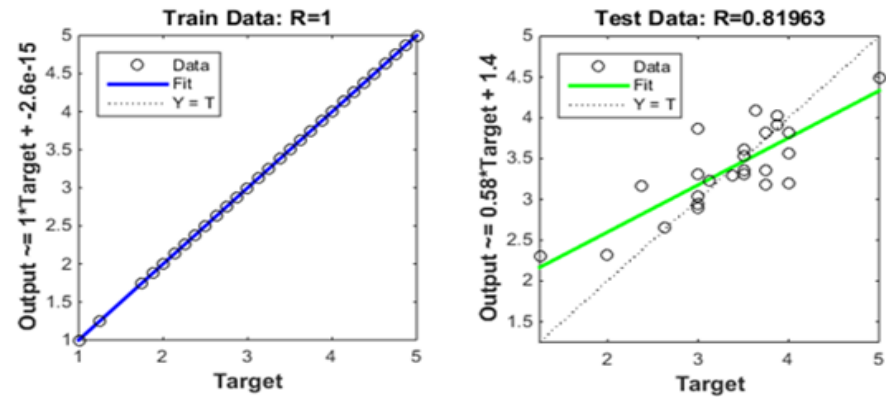

Fig. 4. The calculated correlation between actual data and output data from the model for the best RBF

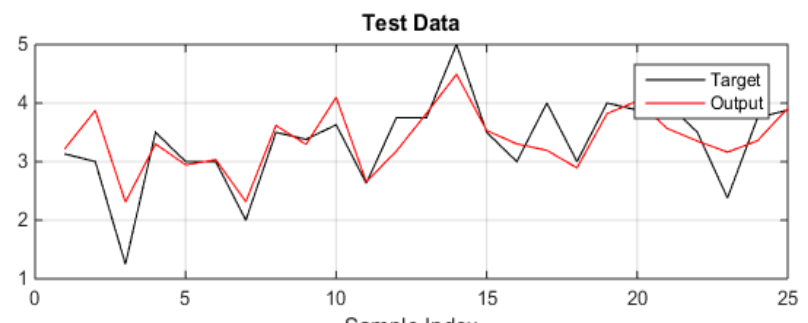

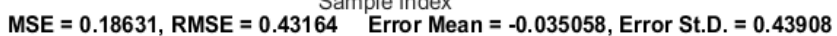

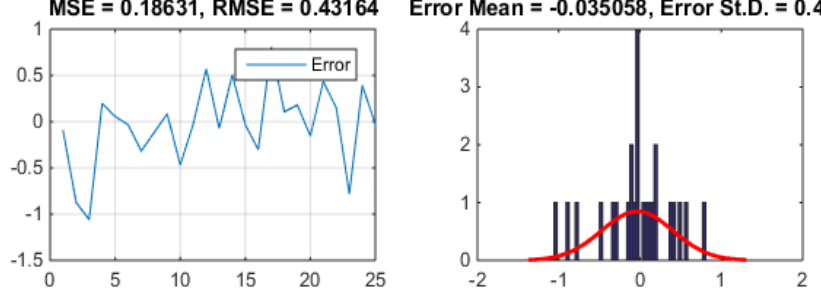

Fig. 5. Results for RBF test data with 225 neurons

TABLE IV. SELECTION OF THE BEST NPD PREDICTION METHOD

\begin{tabular}{|c|c|c|c|}
\hline Prediction method & $\mathbf{R}^{2}$ & RMSE & MSE \\
\hline MLP & 0.49852 & 0.72450 & 0.52490 \\
\hline RBF & 0.67179 & 0.43164 & 0.18631 \\
\hline
\end{tabular}

\section{REFERENCES}

[1] Y. C. Ho, Y-C, C. T. Tsai, "Comparing ANFIS and SEM in linear and nonlinear forecasting of new product development performance", Expert Systems with Applications, Vol. 38, No. 1, pp. 6498-6507, 2011

[2] S. Sheng, Z. K. Zheng Zh, L. Lessassy, L, "NPD speed vs. innovativeness: The contingent impact of institutional and market environments", Journal of Business Research, Vol. 66, No. 1, pp. 23552362,2013

[3] A. La Rocca, P. Moscatelli, A. Perna, I. Snehota, "Customer involvement in new product development in B2B: The role of sales", Industrial Marketing Management, Vol. 58, No. 1, pp. 45-57, 2016

[4] B. Westfechtel, "Models and tools for managing development processes", Springer, Berlin, 1999
[5] M. Crawford, A. Di Benedetto, New Products Management, IrwinMcGraw Hill, 9th edition, 2008

[6] E. Fricke, B. Gebhard, H. Negele, E. Isenberg's, E, "Coping with changes: Causes, findings, and strategies", Systems Engineering, Vol. 3, No. 4, pp. 169-179, 2000

[7] K. Otto, K. Wood, K, "Product Design: Techniques in reverse engineering, systematic design, and new product development", Prentice-Hall, New Jersey, 2001

[8] S. Shane, K. Ulrich, K.(2004), Technological Innovation, Product Development, and Entrepreneurship in Management Science, Management Science, Vol. 50, No. 2, pp.133- 144, 2004

[9] P. S. Ghosal, A. K. Gupta, "Enhanced efficiency of ANN using nonlinear regression for modeling adsorptive removal of fluoride by calcined Ca-Al-(NO3)-LDH”, Journal of Molecular Liquids, Vol. 1, No. 222, pp. 564-570, 2016

[10] L. Zjavka, "Recognition of Generalized Patterns by a Differential Polynomial Neural Network", Engineering, Technology \& Applied Science Research, Vol. 2, No. 1, pp. 167-172, 2012

[11] K. Theofilatos, S. Likothanassis, A. Karathanasopoulos, "Modeling and Trading the EUR/USD Exchange Rate Using Machine Learning Techniques", Engineering, Technology \& Applied Science Research, Vol. 2, No. 5, pp. 269-272, 2012

[12] T. R. Kiran, S. P. S. Rajput, "An effectiveness model for an indirect evaporative cooling (IEC) system: Comparison of artificial neural networks (ANN), adaptive neuro-fuzzy inference system (ANFIS) and fuzzy inference system (FIS) approach", Applied Soft Computing, Vol. 11, No. 4, pp. 3525-3533, 2011

[13] D. H. Lester, "Critical Success Factors for New Product Development", Research Technology Management, Vol. 41, No. 1, pp. 36-43, 1998

[14] J. Pooltan, I. Barclay, "New Product Development from past research to future application", Industrial Marketing Management, Vol. 27, No. 3, pp. 197-212, 1998

[15] A. Di Benedetto, "Identify the key success factor in new product lunch", Journal of Product Innovation and Management, Vol. 16, No. 6, pp. 530$544,2007$.

[16] R. Cooper, "From experience: the invisible success factors in product innovation", Journal of Product Innovation and Management, Vol. 16, No. 2, pp. 115-133, 1999

[17] R. Cooper, E. Kleinschmidt, "What make a new product winner: success factors at the project level", R\&D Management, Vol. 17, No. 3, pp. 175189, 2007

[18] A. Azadeh, M. Saberi, R. Tavakkoli Moghaddam, L. Javanmardi, “An integrated Data Envelopment Analysis-Artificial Neural NetworkRough Set Algorithm for assessment of personnel efficiency", Expert Systems with Applications, Vol. 38, No. 1, pp. 1364-1373, 2011

[19] J. E. Dayhoff, Neural network architectures: an introduction, Van Nostrand Reinhold, New York, 1990

[20] T. Khanna, "Foundation of neural networks", Addison-Wesley Publishing, Boston, 1990

[21] M. M. Gupta, L. Jin, L. Homma, "Static and Dynamic Neural Networks", John Wiley \& Sons, New Jersey, 2003

[22] Z. F. Liu, X. P. Liu, S. W. Wang, G. F. Liu, "Recycling strategy and a recyclability assessment model based on an artificial neural network", Journal of Materials Processing Technology, Vol. 129, No. 1, pp. 500506,2002

[23] J. C. Principe, Artificial Neural Networks, CRC LC Press, University of Florida, 2000

[24] X. Huang, G. N. Soutar, A. Brown, "Measuring new product success: an empirical investigation of Australian SMEs", Industrial Marketing Management, Vol. 33, No. 2, pp. 117-123, 2004 